\title{
Features of modern distance learning for students
}

\section{Características del aprendizaje a distancia moderno para estudiantes}

\author{
DMITRIYEVA, Yelena Y. ${ }^{1}$ \\ DEMTSURA, Svetlana S. ${ }^{2}$ \\ LEBEDEVA, Tatiana $\mathrm{N}^{3}$ \\ SHEFER, Olga R. ${ }^{4}$ \\ MIKHAILOV, Valeriy A. ${ }^{5}$ \\ MIKHAILOVA, Valentina $\mathrm{V}^{6}$ \\ SANNIKOVA Svetlana $\mathrm{V}^{7}$
}

\begin{abstract}
The study examines the features of distance learning for university students from different countries. The current problem has escalated during the pandemic to ensure the safety of students and university staff. The authors pay great attention to the peculiarities of distance learning in Russia, based on an analysis of the literature and regulatory documents. The results obtained show that most universities provide distance learning on modern technical, software, subject, methodological, administrative and management basis and cloud of service support.

Keywords: distance learning of students, technology of distance learning, features of modern distance learning of students.
\end{abstract}

\section{Resumen}

Este estudio analiza las características de la educación a distancia de los estudiantes en universidades de diferentes países. Este problema se ha vuelto muy relevante durante la pandemia para garantizar la seguridad de los estudiantes y el personal universitario. Los autores prestan mucha atención a las peculiaridades de la organización de la educación a distancia en Rusia, basándose en el análisis de la literatura y los documentos normativos. Los resultados indican que la mayoría de las universidades imparten educación a distancia sobre la base de hardware, software, materia, metodología y administración y servicios de apoyo en la nube.

Palabras clave: aprendizaje a distancia de los estudiantes, tecnología del aprendizaje a distancia, características del aprendizaje a distancia moderno de los estudiantes.

\footnotetext{
${ }^{1}$ Saint-Petersburg University of State Fire Service of Emercom of Russia, St.Petersburg, Russia, Candidate of Pedagogical Science, Associate Professor

2 South Ural State Humanitarian Pedagogical University, Department of Economics, management and law, Chelyabinsk, Russia, Candidate of Pedagogical Science, Associate Professor. e-mail: akadem-ppi@mail.ru

3 South Ural State Humanitarian Pedagogical University, Department of Informatics, Informatics Technology and Methodology of Teaching Informatics, Candidate of Pedagogical Science, Associate Professor

4 South Ural State Humanitarian Pedagogical University, Department of «Physics and Methods of Teaching Physics», Chelyabinsk, Russia, Doctor of Pedagogical Sciences, Professor

${ }^{5}$ Saint-Petersburg University of State Fire Service of Emercom of Russia, St.Petersburg, Russia, Candidate of Pedagogical Science, Associate Professor

${ }^{6}$ Saint-Petersburg University of State Fire Service of Emercom of Russia, St.Petersburg, Russia, Candidate of Pedagogical Science, Associate Professor

7 South Ural State Humanitarian Pedagogical University, Department of Foreign Languages, Chelyabinsk, Russia, Candidate of Pedagogical Science, Associate Professor
} 


\section{Introduction}

The pandemic has changed the realities of our life; there have been changes in almost all spheres of Russian society-economic, healthcare, education. There have been changes in Russian education concerning the system itself, technologies and forms of organization of the educational process. In a short time, schools and universities were switched to online format.

The strategy of socio-economic development of Russia until 2025 that determines the need for transition to an innovative model of country development indicates the need for changes in the system of higher professional education (Demtsura, Apukhtin, Fedorova, Sannikova, Yakupov, Rosliakova, Lebedeva and Pluzhnikova, 2019).

Distance learning has been especially actively used in the educational process all over the world since the second half of the twentieth century. In Russian education, the use of distance learning has its own characteristics.

The use of information, communication and distance technologies has led to significant changes in the teaching and learning processes. The inclusion of technology in education involves redefining the dynamics of interaction with students and creating new means of information processing (Aznar, Caceres, Trujillo and Romero, 2019).

Distance learning is the subject of numerous scientific studies.

As I.V. Kiyan noted, in 1939 in France, the National Center for Distance Learning, CNED, was created to teach children who were unable to attend school by mail. Today this center has become the largest distance learning institution in Europe. It consists of eight institutes specializing in a particular field of activity. The total number of employees exceeds 8000 people, and more than 3000 training courses cover a wide range of topics. Over 350,000 students in 120 countries of the world receive education through satellite television, the Internet and e-mail, modern information and educational technologies and educational programs.

In the 70s and 80s of the last century, educational institutions conducting distance learning appeared in a number of other countries of Europe and Asia. Among them are universities in Spain (1972), Pakistan (1974), Thailand (1978), Korea (1982), Indonesia (1984), India (1985), and the Netherlands (1985). In China, the National Network of Radio and Television Universities was established in 1979 to replace traditional higher education institutions that were closed during the Cultural Revolution. Training here is organized using satellite broadcasting and television universities in the province and provides a full range of training levels from elementary to tertiary education for people of all ages. Involving as many citizens of the country as possible in the educational process is only one component of the social order for distance learning, its other aspects become noticeable when analyzing the processes of internationalization. The main reason for the intensive development of the distance learning system is its integrative ability. It is impossible to concentrate in each educational institution all the world's information resources accumulated by humanity in the scientific and educational space, and the task is to provide access to information resources located in any region from every geographic point of the planet where the learning process is organized using telecommunications. the world.

Thus, distance learning activates information resources are distributed across different territories. This is the conceptual rationale and ideology of the need for the development of distance learning.

In this regard, in the European educational community, the practice of joint implementation of educational programs and tasks related to the management of the distance learning system is becoming more widespread. For example, this is evidenced by the collaboration between three higher education institutions in Ireland working in the distance learning sector - Tallaght Institute of Technology (PT, Dublin), Blanchardstown Institute of Technology (ITB) and Dublin City University (DCU), which are involved in collaborative research. aimed at improving the quality of the educational process and the level of education of students for a number of years 
(Kiyan I.V.). For over twenty years, the National University of Distance Education in Spain (UNED) has been working on distance learning programs. 50 universities in the Baltic region are consolidating their efforts to implement distance learning at the Baltic University of Sweden (Kiyan, 2010).

The most widespread development of distance learning is currently in those countries where the appropriate prerequisites have developed for this, namely: a well-developed telecommunications infrastructure, a large territory of the country and a developed system of traditional education. Currently, most American and European universities provide the opportunity to receive education in a distance form, in addition, the number of distance short-term courses in a wide range of disciplines is constantly growing. According to IDC estimates, distance learning occupies a third of the education market in Europe. In Turkey, half of the students study remotely, the barrier of one million students online was passed by the Indira Gandhi National Open University (Kiyan, 2010).

The object of Russian research is the conceptual foundations of modern education in the context of informatization, the influence of informational technologies on the content of education, building an information learning model, application of information technologies for measuring and evaluating learning outcomes, features of open education, development of modern information and communication technologies, teaching on the Internet, new teaching technologies.

The foregoing determines the goal of our research - to identify and describe the features of modern distance learning of students.

\section{Methodology}

An important characteristic of distance learning is the combination of pedagogical methods and techniques used in the educational process. As a criterion, having chosen the way of communication between teachers and students, we have combined these methods into four groups.

First group of methods. Teaching methods through student interaction with educational resources with minimal involvement of the teacher and other students (self-study). To apply these methods, various educational resources have been created: printed, audio and video materials, as well as textbooks delivered via telecommunication networks (interactive databases, electronic publications, computer training systems).

Second group of methods. Methods of individual teaching and learning, which have been characterized by the relationship of one student with one teacher or one student with another student (one-o-one learning). These methods can be implemented in distance learning mainly through technologies like telephone, voice mail, email.

Third group of methods. Methods based on the presentation of educational material by the teacher, while students do not play an active role in communication (one-too-many learning). These methods, characteristic of the traditional educational system, are being re-developed on the basis of modern information technologies. Thus, lectures recorded in audio or video formats become the basis for distance learning. Educational resources are complemented by electronic lectures (a selection of articles, educational materials that prepare students for future discussions). On the basis of electronic bulletin board technology, a method for conducting educational electronic symposia is also being developed, which is a series of speeches by several respected scientists.

Fourth group of methods. Methods characterized by active interaction between all participants in the educational process (many-to-many learning). The value of these methods and the intensity of their use increases significantly with the development of educational telecommunication technologies. It is these methods that have been focused on group work of students and are of the greatest interest for distance learning. These methods involve the widespread use of research and problem learning methods, the application of the knowledge gained 
in joint or individual activities, the development of not only independent critical thinking, but also the culture of communication, and the ability to perform various social roles in joint activities.

\section{Results}

To date, the leading universities are in Germany, Italy, England, Holland, working in the field of open distance learning, have both general development trends and unique features inherent in individual states, educational networks or institutions.

The most important are some of the features of the organization of management, which is directly related to the quality management of pedagogical technologies used in the educational systems of different countries.

The governments of European countries are interested in the development of a distance learning network, but approaches to organizing distance learning and the number of students in different countries differ significantly.

In the UK, for example, distance learning is designed mostly for immigrant specialists - for their early adaptation and integration; in Germany and Holland, the emphasis is on teaching students, and open distance learning is widely used in universities.

The Russian distance learning market is more than twenty years old, and there are already dozens of educational Internet platforms (Lectorium, Universarium, Online-MIPT, HSE Internet School and others). The undisputed Russian leader in this industry is the National Open Education Platform, which offers more than 150 online courses, proctoring system Examus (Vendeker, Galenduhina, Klimenskih, Korepina and Sheka, 2017).

According to official data, by 2025, the Ministry of Science and Higher Education of the Russian Federation has set the task to bring the number of users to 11 million people (Passport of the priority project «Modern digital educational environment in the Russian Federation", 2020). On the one hand, such impressive plans emphasize its humanitarian mission, which is to expand the boundaries of the availability of knowledge. Online education platforms are becoming a kind of social lift, contributing to the implementation of the constitutional right of every Russian to receive an education (Federal Law «On Education» dated December 29, 2012 № 273-FZ).

In Russia, in the context of a pandemic, distance and e-learning is of great importance for the continuation of the educational process.

The decision to transfer the educational process to a distance format is taken independently by universities in different regions of the Russian Federation, based on the level of danger of the epidemiological situation in a particular region, the presence or absence of a threat to students and taking into account different situations for certain categories of students (Order of the Ministry of Science and Higher Education of the Russian Federation of March 14, 2020 № 397).

Order of the Ministry of Science and Higher Education of the Russian Federation № 397 of March 14, 2020, offers educational institutions a choice of two possible scenarios for transferring students to distance learning. The first option, intended for regions with the most difficult epidemiological situation and a high risk of infection, involves the complete cessation of full-time classes and a transition to a completely remote format. In this case, the head of the university must issue an appropriate order for the temporary transfer of students to distance learning. The order must indicate the reason and duration of this decision.

In addition, before the decision comes into force, a certain period should be provided for preparing the university for working in an exclusively remote mode. During this period, all students must be connected to the services of the electronic information and educational environment. This process can take anywhere from two days to two weeks, depending on various factors, including the quality of the university's infrastructure. 
All available electronic teaching materials should be updated for teachers, students and administrative staff. It is supposed to create test assignments, all the necessary announcements should be published, the collection of students' written works should be organized and a grading system should be thought out.

It is necessary to determine which disciplines can be studied by students in the framework of online courses of leading universities, a list of which is posted on the portal of the Ministry of Science and Higher Education of the Russian Federation. If there is no suitable course for a specific academic discipline, you can use lectures in the form of webinars, or provide students with access to lectures previously recorded by teachers. Any suitable technology can be used to communicate between teachers and students, including chats in instant messengers.

The second option of distance learning of students was developed for regions with a non-critical epidemiological situation and consists in the partial transfer of students to distance learning. Those students who express a desire for personal reasons to switch to distance learning will be given such an opportunity.

This format is organized at the university by analogy with the first scenario. In this case, the head of the educational organization also issues a corresponding order, which indicates the decision to transfer students to distance learning at will. In this situation, it should be provided for submission of an application for transfer to an individual curriculum via e-mail or using students' personal accounts in the electronic information educational system.

The order stipulate the need for teachers to interact with students who have chosen a distance learning format. The leader must analyze how to partially or completely transfer disciplines that continue until the end of the current academic year to the distance format, and, by analogy with the first scenario, provide for the transfer of certain disciplines to the next academic year. It is important to note that if the number of students who have expressed a desire to move to a remote format reaches $30 \%$, then the head of the university needs to prepare for the implementation of the first scenario.

Both options for transferring students to distance learning are aimed at ensuring that personal contacts between people in an educational institution are minimized. Russian legislation provides for the possibility of successful implementation of both scenarios. Students are provided with individual curricula, and if necessary, some of the classes can be postponed to the next semester. In both options for transferring students to distance learning, higher education institutions will be helped by open online courses developed by leading Russian universities. In addition, educational institutions have an electronic information and educational environment, organized in accordance with federal state educational standards.

Practice has shown that most Russian universities have chosen the first option.

Speaking about distance learning, it should be noted that this educational technology is aimed at teaching students to independently acquire knowledge on their own.

These events have shown that the lack of a unified concept, lack of practical experience often lead to completely opposite views on this form of education: from reduction to a set of means and methods of transferring educational information to its absolutization, to the emergence of ideas about creating a virtual educational institution, etc.

Distance learning can be interpreted as a process of interaction between a teacher and a student, in which the participants are at a distance from each other, as a result of which the student's knowledge, skills and abilities are formed.

In the Order of the Ministry of Education of Russia, distance learning is understood as learning «provided by the use of a set of educational technologies, in which targeted mediated or incompletely mediated interaction 
between a student and a teacher is carried out regardless of their location and distribution in time on the basis of pedagogically organized information technologies, primarily with use of telecommunication means» (Order of the Ministry of Education of the Russian Federation of 18.12.2002 № 4452).

Having analyzed the features of distance learning, N.Yu. Marchuk identifies its following characteristics (Marchuk, 2013). Distance learning is learning, in which its subjects are separated in space and, possibly, in time, is implemented taking into account the transmission and perception of information in a virtual environment, is provided by a special system for organizing the educational process, a special methodology for developing teaching aids and a teaching strategy, as well as using electronic or other communication technologies.

Distance learning makes it possible to satisfy the individual needs of each person in learning and solve such problems of traditional education as the lack of an individual approach to students, insufficient use of active forms of learning, directive educational process, weak motivation for independent cognitive activity of the student, rigid attachment to the territory and time, subjectivity of assessment of learning outcomes.

The difference between distance learning and traditional learning is the distance between the teacher and the student, the absence of their direct contact in the learning process (Mozhaeva, 1999).

G.V. Mozhaeva describes several options for using distance learning technologies: (1) as an additional support for the main course of study (here distance learning technologies are assigned a supporting role); (2) as a basis for self-education (in this case, students independently acquire and master ready-made electronic educational products, for example, multimedia courses); (3) as the main educational technology. In this case, a permanent group of students has been created in the peripheral center, which works under the guidance and supervision of a teacher-tutor or coordinator. He monitors the course of the educational process, the timely completion of assignments by students, consults, and helps students in the course of mastering the course (Mozhaeva, 1999).

With distance learning, students move away from the usual classroom-lesson system, since they study a significant part of the educational material without a teacher. This requires them to be more independent and clearly organize their working day. The importance of personal motivation for learning activity on the part of students is increasing, the degree of freedom in choosing a range of subjects and the depth of their study increases.

This form assumes independence in the acquisition of knowledge, which should not be passive. In the course of such training, students must first of all learn how to acquire and apply knowledge, seek and find the learning tools and sources of information they need, and be able to work with this information.

The organization of individual or group independent activity of students in the system of distance learning assumes, as in full-time education, the use of the latest pedagogical technologies. First of all, we are talking about the widespread use of the project method, learning in collaboration, research, problem methods.

All of them should help to reveal the internal reserves of each student and at the same time contribute to the formation of social qualities of the individual (the ability to work in a team, performing various social roles, helping each other in joint activities, sometimes solving complex cognitive tasks by joint efforts).

Distance learning, individualized in its essence, should not, at the same time, exclude the possibility of communication not only with the teacher, but also with the student group, cooperation in the process of various kinds of cognitive and creative activities. Socialization problems turn out to be very relevant in distance learning.

Any model of distance learning should provide for a flexible combination of: (1) independent cognitive activity of students with various sources of information, teaching materials specially developed for this course; (2) 
operational and systematic interaction with the lead teacher of the course, consultant-coordinator of the project; (3) group work by type of training in cooperation with the rest of the participants in the course.

Distance from the teacher has a peculiar effect on the psychological state of students - it allows them to feel more relaxed.

However, when creating a system of information support for the educational process in distance learning, it is necessary to take into account the specifics of working with a computer. It manifests itself in the fact that the fatigue of students increases, the load on vision, hearing and brain increases.

This requires careful preparation of didactic means of daytime education, taking into account the sensitivity of the human eye to certain colors, careful selection of fonts, a reasonable combination of various types and forms of educational activity (Mozhaeva, 1999).

Educational institutions in many countries around the world structure the educational process in accordance with the needs of the market and the demand from employers. From a graduate of an educational institution, not only competence in the professional field is required, but also fluency in a computer.

Distance learning presupposes either the presence of such knowledge at the time of admission, or mastering it in a short time. That is, distance learning develops the skills of searching for the necessary information, structuring it, working with it, etc., thereby expanding the general intelligence and thinking.

But in our opinion, the introduction of distance learning requires the psychological readiness of the student and the formed subjective position of the student, which implies an active and conscious personal attitude of the student to the ongoing educational activities (Zaretsky and Sudakova, 2020).

Distant education, due to a number of its features (remoteness, indirect communication, the predominance of students' self-control over control by the teacher) dictates the need for psychological support of this process and providing psychological comfort to its participants.

Motivation is of great importance in distance learning. It is the motivation to acquire solid knowledge that is the driving force for distance learning (Gladkikh, 2015).

At the same time, the methods, methods of study, the interaction of participants in the educational process, the content of educational cycles and the role of subjects of education are changing. Unlike traditional, distance learning is mediated by a virtual environment, and unlike virtual, it involves pedagogical interaction of real subjects of the pedagogical process (Ivanov, 2000).

The transition to distance learning involves careful preparation of materials: software, plans, study guides for program management, manuals, individualization of instructions - and also imposes requirements for technical equipment, information competence of the student and teachers, for the student's personal qualities due to the complexity of educational motivation in this form of training.

Distance learning contains components: subjects of education, a system of communication between subjects, an environment in which the learning process unfolds. If we talk about the environment, then the transfer of information takes place in a special information and educational, virtual environment. The specificity of the environment radically affects all components of learning activity: learning motivation, learning situation, monitoring and assessment of students' learning.

Speaking about the application of the principle of individualization in the educational process, it can be argued that in the process of distance learning, each subject independently builds an individual virtual educational environment, which becomes a factor of his socialization, a means of creating and solving psychological 
problems, a tool for forming a new sociocultural experience. The virtual educational process uses a person's personal educational potential, which develops in those areas that the subject chooses for himself. The subject's virtual educational space reflects the interconnection of all spheres of personality: intellectual, emotional, valuesense, behavioral, etc. The process of expanding the individual virtual educational space occurs as a result of the external and internal mental activity of the subject himself, his self-knowledge, the interpenetration of external and internal (Nosov, 2000).

The lack of direct, direct contact in distance learning accentuates the importance of taking into account the psychological characteristics of the organization of information, which largely determine the effectiveness of learning.

Analysis of scientific material on the organization of distance learning and our own experience allowed us to draw the following conclusions:

When organizing distance learning, it is necessary to remember that the role of a teacher is to maximize the semantic field of educational material, its detailing (Petrova, 2013).

It is necessary to pay attention to the organization of educational material, highlighting its structure, hierarchy according to the criterion of significance and subordination of concepts, including this information in the system of the world as a whole, which should help the student to systematize the material received.

It is necessary to avoid an excess of additional information, so as not to distract students with insignificant information, it is necessary to avoid excessive decoration of educational material with artistic presentation, to adhere to a strictly scientific style. If possible, fill one lesson with one large semantic block.

The temporal aspect of training. First, a certain distribution of training in time is fundamental - the required frequency of classes, consultations, filled with optimal tension, the volume of training material. Secondly, there must be a certain duration of the presentation of the material (necessary for understanding new information), as well as the period of time allotted for processing information, independent study of the material, its expansion, deepening is also important.

An important component of distance learning is the connection between the subjects of the educational process. Therefore, special requirements are imposed on all characteristics of communication - technical, organizational, psychological and pedagogical.

Most researchers pay attention to the special importance of organizing interpersonal communication in the framework of distance learning. The role of feedback in this process is also emphasized.

When organizing distance learning, it is necessary to adhere to the following basic principles of effective interaction: (1) careful organization of didactic dialogue; imitation of dialogue in educational materials; (2) organization of personal support for students in the period between inpatient classes: consultation, provision of important and meaningful information; (3) the distribution of interactive activities in an optimal ratio with the student's independent work.

Deans, teachers and methodologists of faculties and institutes played an important role in organizing interpersonal communication in the framework of distance learning during the pandemic in Russia, communicating with students on social networks, via corporate and personal e-mail.

The implementation of distance learning requires the use of special pedagogical technologies: (1) case technology (based on the preparation for a student of a typical or individual case containing a package with educational literature, a multimedia video course, a virtual laboratory and training programs, anthologies, 
fragments of monographs with teacher's comments, control tasks for self-examination, electronic workbook, etc.); (2) television technology (multi-party video-teleconferencing, one-way video broadcasts); (3) Internet technology (video conferencing, voice mail, chat).

In this case, it is possible to use one of the main technologies and supplement them with other technologies and methods. Currently, there is a tendency towards convergence of various technologies (http://www.tantal.ru/lessons).

\section{Conclusions}

The means of distance learning (as a toolkit for the activities of a teacher and a student) are selected taking into account the specifics of this type of education (Troyan, 2004). The following means are most often used in distance learning: educational publications (in paper and electronic versions); educational websites; network courses; computer training systems (electronic textbooks, simulators, etc.); educational audio and video materials; laboratory remote workshops; databases and knowledge bases with remote access; electronic libraries; expert systems; geographic information systems for educational purposes; virtual reality systems; voice mail; multilateral video teleconferences and one-way video broadcasts; hardware and software for information and communication technologies.

Traditional forms of education in this case also have some organizational features. Firstly, lectures can be implemented in two forms: video conferencing (viewing the speech in real time); independent study of educational materials in various forms (electronic teaching aids, paper textbooks, audio recording, video recording). Secondly, seminars can be organized: in deferred time mode (offline) - text messaging (teleconference); in real time (online) - text exchange (chat), audio conferencing, video conferencing. Thirdly, the workshops involve: independent implementation of practical tasks; remote connection to a laboratory installation (All-Russian server of automated laboratory workshops http://www.alpud.ru); work with a computer model of a laboratory installation (Devterova, 2011). Fourthly, active forms of learning can be organized in the form of: games; situation analysis (case study); group project.

A common characteristic of any form of distance learning is an emphasis on independent work of students and a fractional mode of work, involving short, moderately detailed tasks. A decrease in the effectiveness of educational activities is observed with continuous work for more than 40 minutes (Milovanova, 2014).

Types of control: written assignments; abstracts (in electronic form), essays; term papers; individual projects; automatic online testing; full-time exams; independent and control work; analytical reviews; creative tasks; portfolio; exams; offsets; tests.

Some universities have used methods of student identification, for example, proctoring technology, in examinations and crediting events. Proctoring is a system of remote control of passing the exam and checking the identity of the examiner by specially trained people in order to increase the level of confidence in the results of his certification. This means that during the exam, the students are monitored by a proctor who is located remotely and looks through a webcam. The proctor is the one who observes, that is, the "overseer».

The task of proctoring is to identify the identity of those passing the exam, test, as well as the regulatory support of the process. At the moment, the biometric identification method seems to be effective, since it minimizes the possibility of deception or forgery on the part of the student, and also works to control the normality of behavior in the exam, test (Klimenskikh, Istomin, Khalfin and Panchenko, 2016). 
Experience shows that the assessment of knowledge within the framework of distance learning is most effective with the help of a point-rating system, which allows a more objective assessment of the knowledge of students, encourages them to independently search for materials, to start independent research work.

This work was financially supported by a grant from Shadrinsk State Pedagogical University (application SHK-20-04-16 / 4)

\section{Bibliographic references}

Aznar, I.; Caceres, M.P.; Trujillo, J.M.; Romero, J.M. (2019). Mobile learning and emerging mobile technologies in Preschool Education: perceptions of teachers in training. Espacios. Vol. 40, № 5: 14.

Demtsura, S.S.; Apukhtin, A.A.; Fedorova, K.A.; Sannikova, S.V.; Yakupov, V.R.; Rosliakova, S.V.; Lebedeva, T.N.; Pluzhnikova, I.I. (2019). Pricing policy in the field of marketing of educational services. Espacios. T. 40. № 2: 9.

Devterova, Z.R. (2011). Organizational forms of distance learning and the specifics of their application in the information and educational environment. Actual problems of the humanities and natural sciences. № 9: 202-207.

Federal Law «On Education» dated December 29, 2012 № 273-FZ (2012). Access mode http://www.consultant.ru/document/cons_doc_LAW_140174/e185d59b595b6bf58b8716c9d5129a3dd5b 7630a.

Gladkih, I.B. (2015). Motivation in distance education (Keller's model applies to students with disabilities). Economy and management in the XXI century: development trends. № 25: 58-62.

Ivanov, D.V. (2000). Virtualization of society. SPb .: Petersburg Oriental Studies. 96.

Kiyan, I.V. (2010). Analysis of foreign experience in distance learning. Scientific and methodological problems and new technologies of education. № 6 (36): 32-36.

Klimenskih, M.V.; Istomin, D.V.; Halphin, A.B.; Panchenko, V.N. (2016). Providing the procedure for distance examination activities by means of student identification methods. Bulletin of Kazan State Power Engineering University. Issue 3 (31): 134-151.

Marchuk, N.Y. (2013). Psychological and pedagogical features of distance learning. Pedagogical education in Russia. № 4: 78-85.

Milovanova, G.V. (2014). Independent work of students in the context of distance education. Humanities: topical problems of the humanities and education. № 3 (27): 72-77.

Mozhaeva, G.V. (1999). The educational process in the distance education system. Bulletin of the Association "Open University of Western Siberia». Issue 1: 40-49.

Nosov, N. (2000). Virtual psychology. Moscow: Agraf. 432.

Order of the Ministry of Education of the Russian Federation of 18.12.2002 № 4452. On approval of the Methodology for the use of distance educational technologies (distance learning) in educational institutions of higher, secondary and additional professional education in the Russian Federation. Access mode: https://legalacts.ru/doc/prikaz-minobrazovanija-rf-ot-18122002-n-4452/. 
Order of the Ministry of Science and Higher Education of the Russian Federation of March 14, 2020 № 397 «On the organization of educational activities in organizations implementing educational programs of higher education and corresponding additional professional programs, in the context of preventing the spread of a new coronavirus infection in the Russian Federation». Access mode:

https://minobrnauki.gov.ru/ru/documents/card/?id_4=1064.

Passport of the priority project «Modern digital educational environment in the Russian Federation» (2016). Access mode: http://static.government.ru/media/files/8SiLmMBgjAN89vZbUUtmuF5IZYfTVOAG.pdf.

Petrova, L.V. (2013). Psychological and pedagogical technologies for creating a virtual educational environment for intercultural interaction. Pedagogical education in Russia. № 4: 139-142.

Troyan, G.M. (2004). Application of universal approaches to improve the quality of distance education. Open education. № 2: 37-47.

Vendeker, O.S.; Galenduhina, E.A.; Klimenskih, M.V.; Korepina, N.A.; Sheka, A.S. (2017). On the question of the effectiveness of distance learning: exploration of views. Pedagogical education in Russia. № 10: 41-47.

Zareckyi, V.K; Sudakova L.V. (2020). Assistance in overcoming learning difficulties by means of a reflexiveactivity approach in distance learning: the case of Mitya. Counseling psychology and psychotherapy. T. 28. № 2: 120-136.

\section{(cc) EY-NC}

